\title{
Validation of a Mathematical Procedure for the Cobb Angle Assessment Based on Photogrammetry
}

\author{
Isis Juliene Rodrigues Leite Navarro, MS, Cláudia T. Candotti, PhD, Tássia S. Furlanetto, PhD, \\ Vinícius H. Dutra, PT, Maiane A. do Amaral, PT, and Jefferson F. Loss, PhD
}

ABSTRACT

\begin{abstract}
Objective: This prospective study aimed to assess the concurrent validity and diagnostic accuracy of a mathematical procedure for measurement of the spinal inclination angle, analogous to the Cobb angle, by means of photogrammetry. Methods: Sixty-one subjects (aged 7 to 18 years), male and female, underwent radiographic (Cobb angle) and photogrammetric (DIPA [Digital Image-based Postural Assessment] angle) evaluations. The measurement of spinal inclination angle obtained through photogrammetry followed the Digital Image-Based Postural Assessment software protocol. Concurrent validity was appraised using Spearman rank correlation, the coefficient of determination, the root-mean-square error, Bland-Altman plot analysis, and receiver operating characteristic analysis, adopting $P \leq .05$.
\end{abstract}

Results: The analyses were divided according to the topography of the scoliotic curve (thoracic, lumbar, or thoracolumbar). The correlations were excellent (from 0.72 to 0.81 ) and significant for all the regions of the spine, and the coefficients of determination ranged between 0.75 and 0.88 . The root-mean-square error was between $5^{\circ}$ and $11^{\circ}$, and the mean difference was very close to 0 . The area under the curve was excellent and significant, ranging between $95 \%$ and $99 \%$.

Conclusion: The mathematical procedure presented is valid to evaluate the spinal inclination angle in photogrammetry, analogous to the Cobb angle in radiography. (J Chiropr Med 2019;18;270-277)

Key Indexing Terms: Scoliosis; Photogrammetry; Posture

\section{INTRODUCTION}

Adolescent idiopathic scoliosis (AIS) is a 3-dimensional deformity that alters the posture of the spine and the trunk. The Cobb angle measure obtained by radiologic examination is used for diagnosis and monitoring of the progression of the scoliotic curve. ${ }^{1}$ However, the effects of ionizing radiation on the human body have been investigated, and the oncogenic potential of repeated exposure to those rays is known. ${ }^{2}$

Considering the age range of the individuals diagnosed with AIS and the fact that these individuals are in the growth stage, the deleterious effects of ionizing radiation

Biomechanics Department, Universidade Federal do Rio Grande do Sul, Porto Alegre, Rio Grande do Sul, Brazil.

Corresponding author: Isis Juliene Rodrigues Leite Navarro, MS, Universidade Federal do Rio Grande do Sul, ESEFID/ LAPEX/BIOMEC, Rua Felizardo, 750, Jardim Botânico 248, Porto Alegre, Rio Grande do Sul 90660030, Brazil.

(e-mail: isisjlnavarro@gmail.com).

Paper submitted May 26, 2018; in revised form November 25, 2018; accepted January 16, 2019.

1556-3707

(C) 2020 by National University of Health Sciences.

https://doi.org/10.1016/j.jcm.2019.01.001 become of even more concern. ${ }^{3}$ In addition, the need for a radiology room and specialized professionals, which raise the cost of the exam and sometimes the poor image quality, are negative aspects attributed to radiography as well. ${ }^{4}$

It is therefore important to be able to use alternative noninvasive methods that can diagnose and monitor AIS while reducing exposure to $\mathrm{x}$-rays. Clinical evaluation of body posture, ${ }^{5}$ surface topography, ${ }^{6,7}$ and photogrammetry associated with postural evaluation software ${ }^{8,9}$ are some of these methods.

Regarding these noninvasive methods, photogrammetry presents advantages such as the absence of ionizing radiation, the availability of validated and free software programs, and the use of a basic infrastructure (tripod, camera, markers, and plumb line). ${ }^{9}$ However, not all of the available software provides clinical information equivalent to that obtained from radiography.

In this sense, the objective of the present study was to assess the concurrent validity and diagnostic accuracy of a mathematical procedure to measure the spinal inclination angle, equivalent to the Cobb angle measurement, using photogrammetry. We hypothesized that photogrammetry is capable of estimating the spinal inclination angle in the frontal plane, analogous to the Cobb angle in radiography. 


\section{MethODS}

\section{Study Design}

This study was a prospective study for diagnostic test assessment reported to STARD (Standards for Reporting Diagnostic Accuracy). ${ }^{10}$

\section{Participants}

Anteroposterior and posteroanterior full-spine radiographs were obtained from a consecutive sample of 61 children and adolescents of both sexes. Eligibility criteria were having a full-spine radiograph requested by a doctor, presenting a chronological age of 7 to 18 years, being able to maintain an upright position without help, and not having undergone surgical intervention in the spine. Individuals presenting spina bifida, sixth lumbar vertebra, or fewer than 12 thoracic vertebrae were excluded from the sample.

This study was approved by the Research Ethical Committee (66785817.4.0000.5347). Individuals were included in the study if they agreed to participate and only after their parents signed the informed consent form before the assessments. Participants were identified through social network communication (Facebook, blog, WhatsApp) from January through December 2017, based on a full-spine radiograph.

\section{Test Methods}

The data was collected and analyzed in 2 steps: (1) clinical postural evaluation using photogrammetry, and (2) radiologic evaluation.

For both evaluations, the participants wore adequate clothing, like bathing suits, tank tops, and shorts. The evaluator was an experienced physiotherapist (8 years) specializing in scoliosis assessment who performed blind and independent assessments of the radiographs and photographs. In 53\% of the cases, steps 1 and 2 were performed on the same day; in the other $47 \%$, there was a time interval from 7 to 30 days between steps 1 and 2. No clinical intervention occurred between steps.

Clinical Postural Evaluation Using Photogrammetry. Participants were submitted to a photographic register in orthostatic posture. They adopted the same position of upper and lower limbs as in the obtention of the radiographs. As a reference, a plumb line with 2 reflexive markers was
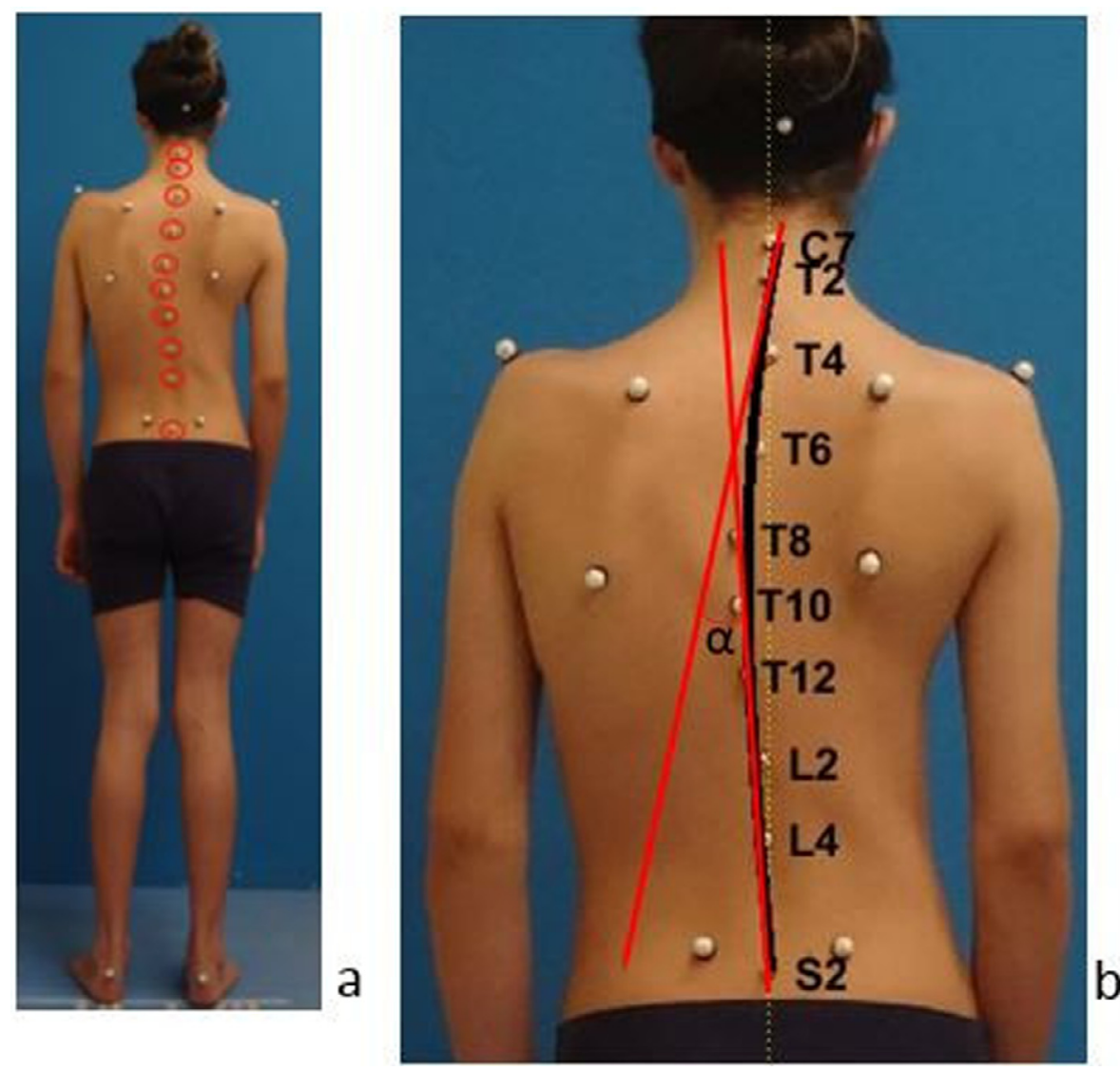

Fig I. In highlight, the reference anatomical landmarks used for the analysis of the spinal inclination angle (A) and analysis of the spinal inclination angle in the photograph (B). The red lines form the DIPA (Digital Image-Based Postural Assessment) angle. They are tangent to the cranial and caudal vertebrae chosen by the examiner. 
positioned beside the participant, in line with the heel. The digital camera (Sony Cybershot DSC-F717, 5.0 megapixels, $512 \mathrm{Mb}$ of memory, $5 \times$ optical zoom and $10 \times$ digital zoom) was attached to a tripod at a height of $0.95 \mathrm{~m}$ and $3.0 \mathrm{~m}$ horizontally distant from the individual. ${ }^{9}$

Some reference anatomic landmarks (ALs) were marked for the photographic register. Reflexive markers were attached to the skin with double-sided tape on the spinous process of the C7, T2, T4, T6, T8, T10, T12, L2, L4, and S2 vertebrae (Fig 1A). After photographs were obtained, the images were analyzed on the DIPA (Digital Imagebased Postural Assessment) software, which calculated the spinal inclination angle based on the ALs using the tangent method (Fig 1B). In order for DIPA to perform the calculation of the spinal inclination angle, the evaluator should have digitalized all the ALs marked on the participant in the photograph, decided which spinous processes would represent the upper and the lower limits of the curvature, and entered it into the software. When the definition of the cranial vertebra or the caudal vertebra of the curvature was dubious, more than 1 analysis was performed on the software, but only the measurement resulting in the wider angle was considered for statistical analysis.

There are no cutoff values for the spinal inclination angle established by photogrammetry. Based on the findings of this research, we might suggest some.

Radiologic Evaluation. The full-spine radiographs were obtained at a hospital by an experienced radiologist, according to the standard radiographic positioning. In these examinations, the participants remained in a relaxed orthostatic posture, with the trunk against the grid, maintaining the upper limbs at the side of the body and the feet and knees together and parallel, but respecting their natural posture. Also, participants sustained inspiratory apnea during the obtention of the radiograph.

The Cobb angle was calculated in the radiographs according to the 2-line Cobb method ${ }^{11}$ and using a mathematical routine in MATLAB version 7.9 software. The scoliotic curve was determined by the upper end plate of the cranial vertebra with the greatest inclination and the lower end plate of the caudal vertebra with the greatest inclination (Fig 2).

The Cobb angle measured in radiography has been described in the literature as the gold standard for the diagnosis of scoliosis. ${ }^{12,13}$ However, the use of this exam involves exposure to ionizing radiation that has deleterious effects highlighting the oncogenic potential. The Scoliosis Research Society has established a Cobb angle cutoff point of $10^{\circ}$ to indicate the presence of scoliosis. ${ }^{14,15}$ Cases with values under that cutoff are not considered a pathological situation and can be described as functional or postural scoliosis. ${ }^{16}$

\section{Analysis}

There were no indeterminate results or missing data for either the photogrammetry or radiographic evaluations.

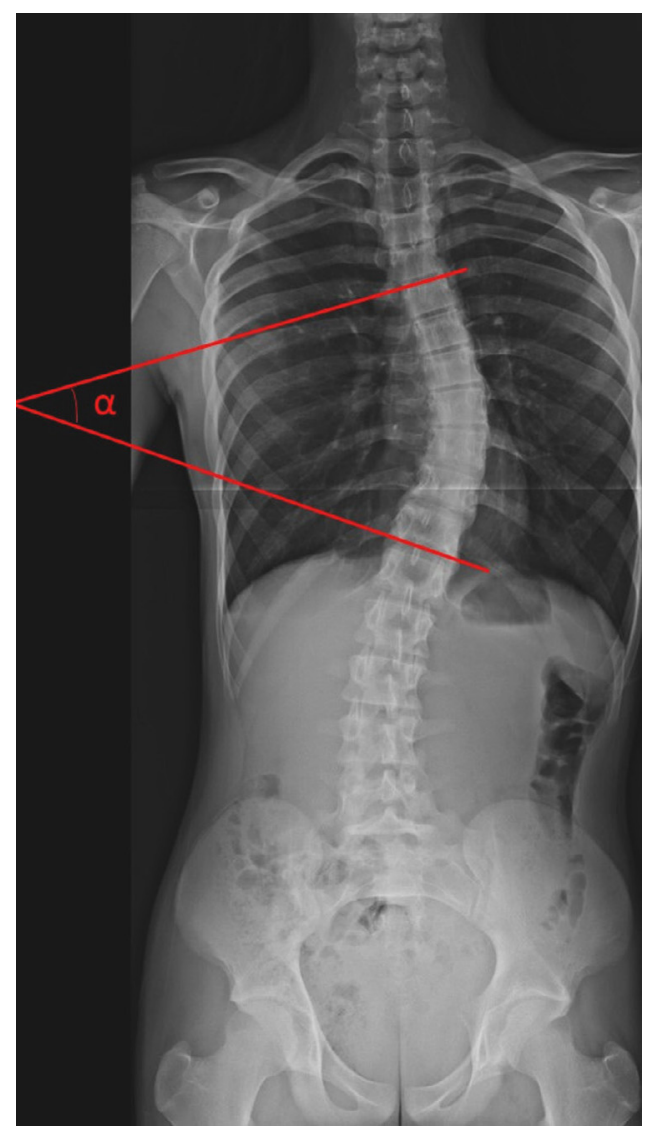

Fig 2. Measurement of the Cobb angle in radiographic examination (anteroposterior projection).

The data was analyzed with SPSS version 21.0. Initially, the Kolmogorov-Smirnov test was performed, followed by a descriptive analysis of the data and measures of central tendency and dispersion. The validity was appraised using Spearman rank correlation, the coefficient of determination, root-mean-square (RMS) error, and Bland-Altman plot analysis. Correlations were categorized as weak $(0.10-$ $0.29)$, moderate $(0.30-0.49)$, or excellent $(0.50-1.0){ }^{17}$ Diagnostic accuracy was appraised using MedCalc software to make a receiver operating characteristic (ROC) analysis. The area under the curve (AUC) was classified according to Hanley and $\mathrm{McNeil}^{18}$ as poor (0.60-0.69), regular (0.70-0.79), or excellent $(\geq 0.90)$. The significance level for all tests was $\leq .05$. The sample size was calculated using $\mathrm{G}^{*}$ Power version 3.1.9.2 software adopting a power of $90 \%$ and probabilistic error of $5 \%$ with $\mathrm{H}_{1} r=0.6$ and $\mathrm{H}_{0} r=0.3$, resulting in an estimated $\mathrm{n}$ of 61 subjects.

\section{RESULTS}

\section{Participants}

The flow of participants is described in the flowchart (Fig 3). Participants had a mean $( \pm$ SD) age of $11.9( \pm 3.4)$ 


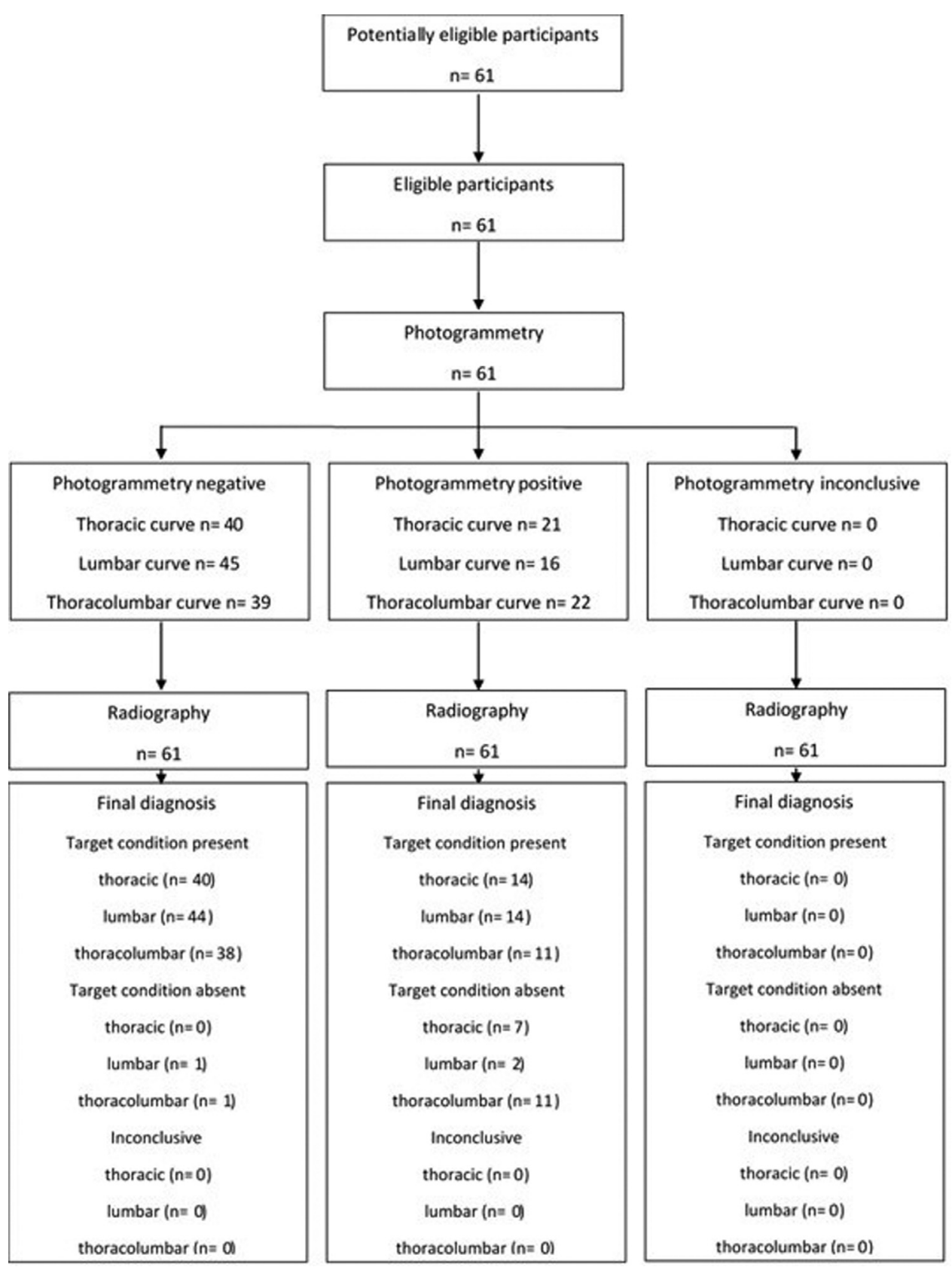

Fig 3. Flowchart of the participants.

years, a mean body mass of $44.5( \pm 15.6) \mathrm{kg}$, and a mean height of $1.5( \pm 0.2) \mathrm{m}$. There was no sample loss. Regarding the vertebral inclination angle, in the thoracic region 47 participants presented a Cobb angle less than $10^{\circ}, 7$ participants between $10^{\circ}$ and $45^{\circ}$, and 7 participants greater than $45^{\circ}$. In the lumbar region, 46 participants presented a Cobb angle less than $10^{\circ}, 11$ participants between $10^{\circ}$ and $45^{\circ}$, and 4 participants greater than $45^{\circ}$. In the thoracolumbar region, 49 participants presented a Cobb angle less than $10^{\circ}, 9$ participants between $10^{\circ}$ and $45^{\circ}$, and 3 participants greater than $45^{\circ}$.
In all analyses (thoracic, lumbar, and thoracolumbar), the correlations between the radiographs and the photographs were excellent, and the RMS error was acceptable ( $5^{\circ}$ to $11^{\circ}$; Table 1$)$.

\section{Test Results}

In the Bland-Altman plot analysis of the thoracic region, the mean difference was very close to $0\left(0.0002^{\circ}\right)$. The upper and lower limits of agreement were $23.3^{\circ}$ and 
Table I. Mean (range) of the Angles in Radiographic Examinations and Photographs, Correlation Analysis, Dispersion Analysis, Linear Regression Analysis, and Root-Mean-Square Error

\begin{tabular}{llllllll}
\hline Region & Cobb Angle & DIPA Angle & $\rho$ & $R^{2}$ & Angular Coefficient & Intercept & RMS Error \\
\hline Thoracic & $13^{\circ}\left(0^{\circ}-115^{\circ}\right)$ & $15^{\circ}\left(1^{\circ}-124^{\circ}\right)$ & $0.72^{\mathrm{a}}$ & 0.80 & 1.608 & 3.578 & $11^{\circ}$ \\
Lumbar & $8^{\circ}\left(0^{\circ}-75^{\circ}\right)$ & $7^{\circ}\left(0^{\circ}-87^{\circ}\right)$ & $0.81^{\mathrm{a}}$ & 0.75 & 2.099 & -0.352 & $9^{\circ}$ \\
Thoracolumbar & $7^{\circ}\left(0^{\circ}-76^{\circ}\right)$ & $7^{\circ}\left(0^{\circ}-77^{\circ}\right)$ & $0.77^{\mathrm{a}}$ & 0.88 & 1.470 & 0.382 & $5^{\circ}$ \\
\hline
\end{tabular}

DIPA, Digital Image-based Postural Assessment; $\rho$, Spearman rank correlation coefficient; $R M S$, root-mean-square.

a $P<.05$

$-23.3^{\circ}$. The data were scattered, and only 4 outliers were above the superior limit (Fig 4).

For the lumbar region, the mean difference was close to 0 as well $\left(-0.0013^{\circ}\right)$. The upper and lower limits of agreement were $17.2^{\circ}$ and $-17.2^{\circ}$. The data were scattered, and 3 outliers were above the upper limit and 2 below the lower limit (Fig 5).

For the thoracolumbar region, the mean difference was 0 $\left(0^{\circ}\right)$. The upper and lower limits of agreement were $11.7^{\circ}$ and $-11.7^{\circ}$. The data were scattered, and only 4 outliers were above and below the upper and lower limits (Fig 6).

The ROC curve analysis demonstrated excellent and significant AUC for all regions (thoracic, lumbar, and thoracolumbar), and it was possible to establish cutoff points for the spinal inclination angle in the photogrammetry (Table 2). No adverse events occurred when the evaluations were performed.

\section{DISCUSSION}

The use of photogrammetry for screening, diagnosing, and monitoring individuals with scoliosis has become more popular in clinical practice. It is a trustworthy and easy-to- use instrument for researchers and clinicians that also contributes to the reduction of patient exposure to ionizing radiation. ${ }^{19,20}$ In photogrammetry, some efforts have been made to improve this instrument, like standardization of procedures for data collection and processing of results. However, to the best of our knowledge there is no software capable of measuring the spinal inclination angle similarly to the Cobb angle. ${ }^{19}$

Using photogrammetry, de Souza et $\mathrm{al}^{21}$ identified scoliosis in $68 \%$ of their evaluated participants. However, the concurrent validity and accuracy of the protocol and software used do not assure the trustworthiness of their results in comparison to the gold standard, the radiographic examination. Furthermore, Ferreira et $\mathrm{al}^{22}$ found $78.7 \%$ prevalence of scoliosis in schoolchildren using photogrammetry. Both studies evidence the usefulness and applicability of photogrammetry in clinical and school environments. On the other hand, it should be noted that these authors base their evaluation of scoliosis on software that is not compared with the gold standard. Concurrent validation is not appraised in the frontal plane in these studies, ${ }^{23}$ and this may weaken their findings.

Based on the results we obtained and regarding the methodology proposed in this study, it is possible to measure the spinal inclination angle through photogrammetry (DIPA

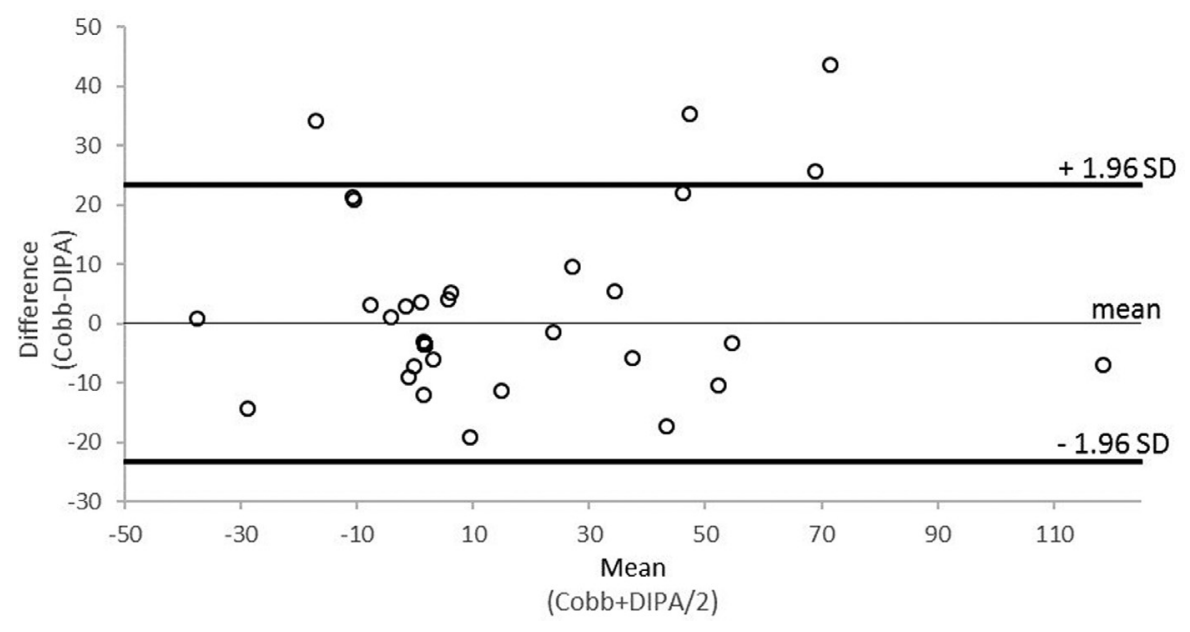

Fig 4. Bland-Altman plot analysis of the thoracic region. $S D$, standard deviation. 


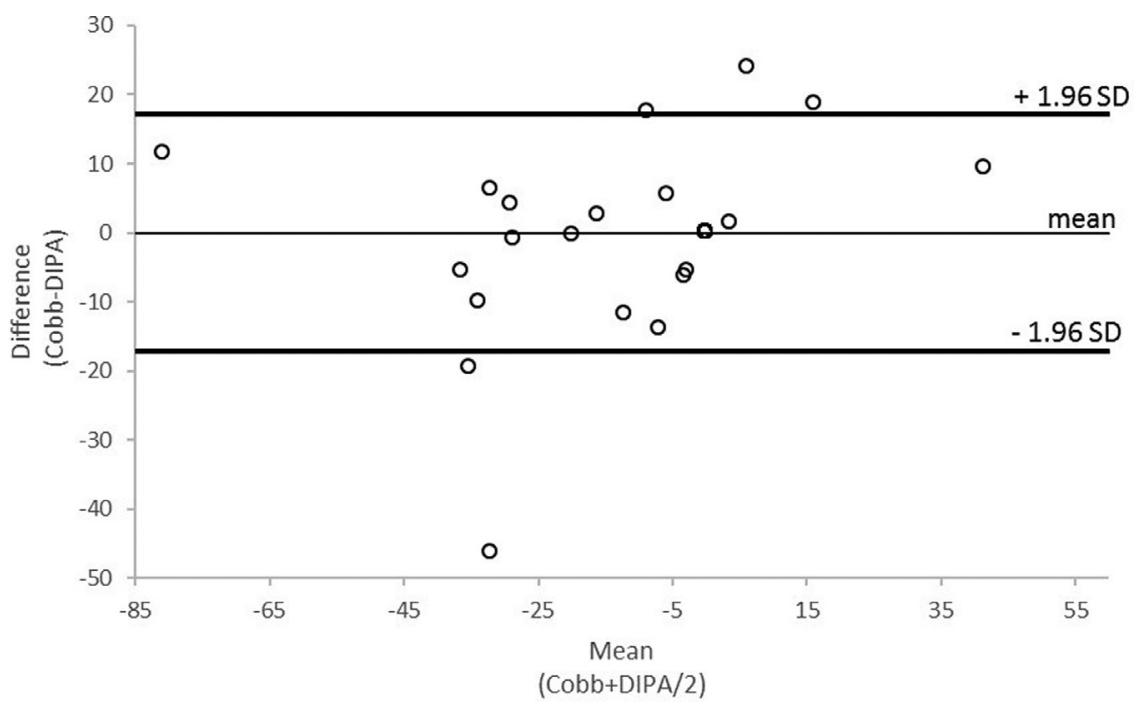

Fig 5. Bland-Altman plot analysis of the lumbar region. $S D$, standard deviation.

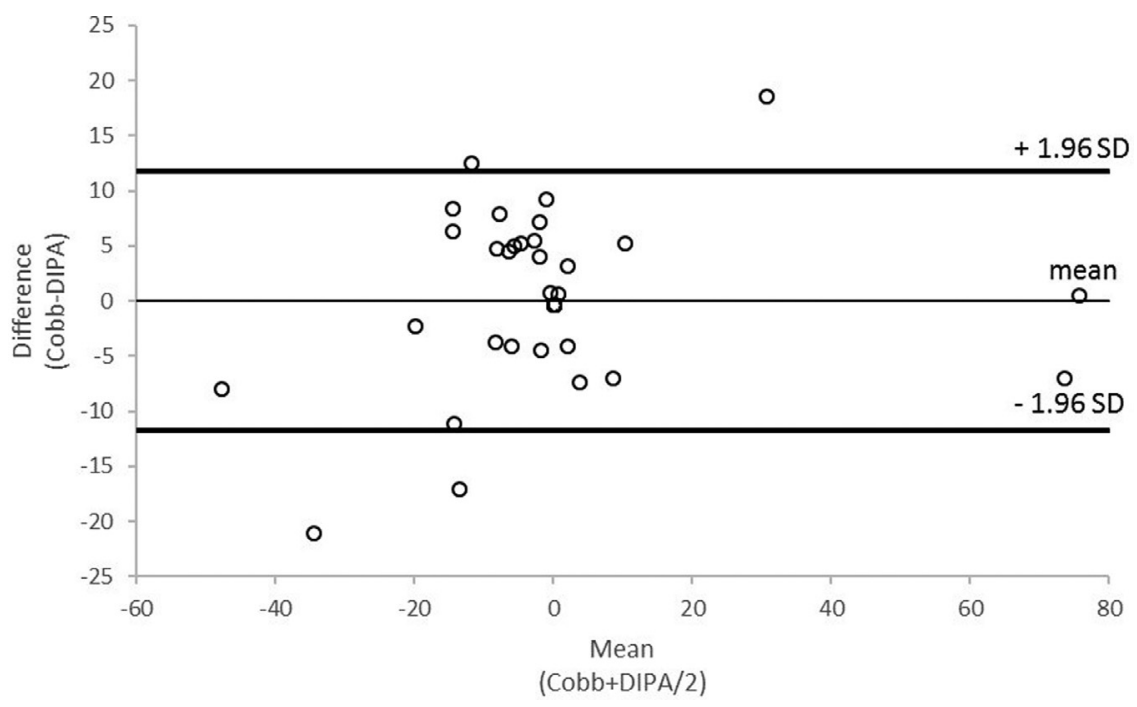

Fig 6. Bland-Altman plot analysis of the thoracolumbar region. SD, standard deviation.

Table 2. ROC Curve Analysis for Thoracic, Lumbar, and Thoracolumbar Regions

\begin{tabular}{llllll}
\hline Region & $\begin{array}{l}\text { Cutoff } \\
\text { point }\end{array}$ & $\begin{array}{l}\text { Sensitivity } \\
(\%)\end{array}$ & $\begin{array}{l}\text { Specificity } \\
(\%)\end{array}$ & $\begin{array}{l}\text { AUC } \\
(\%)\end{array}$ & $\begin{array}{l}95 \% \mathrm{CI} \\
(\%)\end{array}$ \\
\hline Thoracic & $5.4^{\circ}$ & 100 & 83 & $99^{\mathrm{a}}$ & $97-100$ \\
Lumbar & $4.4^{\circ}$ & 93 & 99 & $95^{\mathrm{a}}$ & $87-100$ \\
Thoracolumbar & $5.2^{\circ}$ & 92 & 77 & $95^{\mathrm{a}}$ & $89-100$ \\
\hline
\end{tabular}

$A U C$, area under the curve; $C I$, confidence interval; $R O C$, receiver operating characteristic.

${ }^{\text {a }} P<.001$ angle), analogous to the Cobb angle. The robustness of the results is confirmed by the statistical analyses, which show that the correlation between the measures is excellent and significant. The results of both instruments do not differ.

Accuracy is an essential requirement when choosing an evaluation method. The Cobb angle method, which is considered the gold standard, presents $3^{\circ}$ and $5^{\circ}$, respectively, of intrarater and interrater standard error. ${ }^{24}$ RMS error is an accuracy measure that indicates the average magnitude of the error between the predicted value and the real observation. ${ }^{25}$ In the present study, the RMS error ranged between $5^{\circ}$ and $11^{\circ}$ (Table 1 ). For example, in the thoracic region, the RMS error of $11^{\circ}$ may be considered an acceptable error because the measures vary from $1^{\circ}$ to $124^{\circ}$. The results for the other curvatures were even better: lumbar RMS error 
was $9^{\circ}$ and thoracolumbar was $5^{\circ}$. This indicates the good accuracy of the proposed method compared with the gold standard for quantifying scoliotic curvature in any region of the spine, based on the spinal inclination angle.

The dispersion analysis between the measures (Cobb and DIPA) presented consistent determination coefficients between .75 and .88. Furthermore, it was possible to develop a prediction equation that allowed the correction of the predicted value (DIPA) according to the observed values (Cobb). Thus, the magnitude of the DIPA angle was equated to the Cobb angle in each case. The use of this mathematical procedure allows the DIPA user to estimate the Cobb angle on a photograph.

Concordance between measures is another fundamental aspect in the process of validating a new instrument, and many researchers have been using this approach. ${ }^{23,26}$ Bland and Altman assert that an isolated analysis of the coefficients of correlation and determination does not guarantee the concordance between the appraised instruments, so they propose the use of a plot analysis that allows for determining the concordance between methods, establishing a confidence interval and the mean difference between measures from both instruments. ${ }^{27}$ In our study, the plot analysis of each region of the spine showed good results because the mean difference between methods was very close or equal to 0 .

In our study, we found very high AUC values for all regions (thoracic, lumbar, and thoracolumbar) of the spine, and we must consider that the AUC is an estimator of the global test performance. ${ }^{28}$ Previous researchers have reported adequate accuracy with an AUC of around $85 \%$ in the evaluation of the spine by means of a surface topography relative to radiographic examination. ${ }^{29}$ Also, the ROC curve analysis allowed us to establish cutoff points for photogrammetry. In all regions, it was possible to find high values for both sensitivity and specificity for each cutoff point. We highlight that the use of a classification based on these cutoff points has an important place in clinical practice.

\section{Study Limitations}

One limitation of our research is the nonstandardized time interval between the radiographic and photogrammetric evaluations, which varied from 7 to 30 days. This time gap between evaluations may have affected the results obtained. Also, it is important to mention that AIS is a 3dimensional deformity ${ }^{30}$ and should be assessed in all planes (frontal, sagittal, and transverse). However, radiography and photogrammetry are 2-dimensional evaluation methods. In this aspect, technological advances and methodological improvements in the current protocols and software programs are needed to broaden the scope of the evaluation of individuals with AIS.

In summary, the results found in our research suggest good accuracy for the proposed method. The mathematical procedure presented is valid to calculate the spinal inclination angle by means of photogrammetry, as is the Cobb angle in radiography. We highlight that our findings confirm the possibility of considering photogrammetry as an alternative tool for the evaluation and quantification of scoliotic curvature in children and adolescents, avoiding the repeated exposure of these individuals to x-rays. We also emphasize the low cost, availability, and uncomplicatedness of this instrument, which make it an excellent alternative for clinical use.

\section{Funding SOURCES AND CONFLICTS OF INTEREST}

The first author of this study received funding from the Conselho Nacional de Desenvolvimento Científico e Tecnológico of Brazil. There were no conflicts of interest reported.

\section{CONTRIBUTORSHIP INFORMATION}

Concept development (provided idea for the research): I.J.R.L.N., C.T.C.

Design (planned the methods to generate the results): I.J.R.L.N., C.T.C.

Supervision (provided oversight, responsible for organization and implementation, writing of the manuscript): I.J.R.L.N., C.T.C.

Data collection/processing (responsible for experiments, patient management, organization, or reporting data): I.J.R.L.N., T.S.F., M.A.A.

Analysis/interpretation (responsible for statistical analysis, evaluation, and presentation of the results): I.J.R.L.N., T.S.F., V.H.D., M.A.A., J.F.L.

Literature search (performed the literature search): I.J.R.L.N., M.A.A.

Writing (responsible for writing a substantive part of the manuscript): I.J.R.L.N., M.A.A.

Critical review (revised manuscript for intellectual content, this does not relate to spelling and grammar checking): I.J.R.L.N., C.T.C.

\section{Practical Applications}

- This article presents an alternative tool to radiographic exams in evaluation of the spine on the frontal plane.

- The results evidence the validity of photogrammetry for measuring the Cobb angle.

- The article collaborates in the development and improvement of photogrammetry for posture evaluation.

- The proposed method allows decreased exposure to ionizing radiation for individuals with scoliosis. 


\section{REFERENCES}

1. Knott P, Pappo E, Cameron M, et al. SOSORT 2012 consensus paper: reducing $\mathrm{X}$-ray exposure in pediatric patients with scoliosis. Scoliosis. 2014;9(1):4.

2. Pace N, Ricci L. A comparison approach to explain risks related to X-ray imaging for scoliosis. Scoliosis. 2013;8(1):O37.

3. Kotwicki T, Negrini S, Grivas TB, et al. Methodology of evaluation of morphology of the spine and the trunk in idiopathic scoliosis and other spinal deformities -6th SOSORT consensus paper. Scoliosis. 2009;4(1):26.

4. Larson JE, Meyer MA, Boody B, Sarwark JF. Evaluation of angle trunk rotation measurements to improve quality and safety in the management of adolescent idiopathic scoliosis. J Orthop. 2018;15(2):563-565.

5. Santos A. Diagnóstico Clínico Postural: Um Guia Prático. São Paulo, Brazil: Summus Editorial; 2001.

6. Sedrez JA, Candotti CT, Rosa MIZ da, Medeiros F da S, Marques MT, Loss JF. Validation of a topography system for evaluation spine in sagittal plane for children in different nutrient profiles. Fisioter e Pesqui. 2016;23(2):163-171.

7. Knott P, Sturm P, Lonner B, et al. Multicenter comparison of 3D spinal measurements using surface topography with those from conventional radiography. Spine Deform. 2016;4(2):98103.

8. Suaide ALA do P. Desenvolvimento e Validação de Uma Ferramenta Computacional para Mensuração das Curvaturas da Coluna Vertebral. São Paulo, Brazil: University of São Paulo; 2008. [master's thesis].

9. Furlanetto TS, Candotti CT, Comerlato T, Loss JF. Validating a postural evaluation method developed using a Digital Image-based Postural Assessment (DIPA) software. Comput Methods Programs Biomed. 2012;108(1):203-212.

10. Bossuyt PM, Reitsma JB, Bruns DE, et al. STARD 2015: an updated list of essential items for reporting diagnostic accuracy studies. Clin Chem. 2015;61(12):1446-1452.

11. Harrison DE, Cailliet R, Harrison DD, Janik TJ, Holland B. Reliability of centroid, Cobb, and Harrison posterior tangent methods: which to choose for analysis of thoracic kyphosis. Spine (Phila Pa 1976). 2001;26(11):e227-e234.

12. Pruijs JEH, Hageman MAPE, Keessen W, van der Meer R, van Wieringen JC. Variation in Cobb angle measurements in scoliosis. Skeletal Radiol. 1994;23(7):517-520.

13. Morrissy RT, Goldsmith GS, Hall EC, Kehl D, Cowie GH. Measurement of the Cobb angle on radiographs of patients who have scoliosis: evaluation of intrinsic error. $J$ Bone Joint Surg Am. 1990;72(3):320-327.

14. Wilson PL, Newton PO, Wenger DR, et al. A multicenter study analyzing the relationship of a standardized radiographic scoring system of adolescent idiopathic scoliosis and the Scoliosis Research Society outcomes instrument. Spine (Phila Pa 1976). 2002;27(18):2036-2040.

15. Weinstein SL. Natural history. Spine (Phila Pa 1976). 1999;24(24):2592-2600.
16. Negrini S, Aulisa L, Ferraro C, et al. Italian guidelines on rehabilitation treatment of adolescents with scoliosis or other spinal deformities. Eura Medicophys. 2005;41(2):183-201.

17. Cohen J. Statistical Power Analysis for the Behavioral Sciences. 2nd ed. Hillsdale, NJ: Lawrence Erlbaum Associates; 1988.

18. Hanley JA, McNeil BJ. The meaning and use of the area under a receiver operating characteristic (ROC) curve. Radiology. 1982;143(1):29-36.

19. Stolinski L, Kozinoga M, Czaprowski D, et al. Two-dimensional digital photography for child body posture evaluation: standardized technique, reliable parameters and normative data for age 7-10 years. Scoliosis Spinal Disord. 2017;12 (1):38 .

20. Romano M, Mastrantonio M. Torsion bottle, a very simple, reliable, and cheap tool for a basic scoliosis screening. Scoliosis Spinal Disord. 2018;13(1):4.

21. de Souza CEA, de Lima Neto JJ, Lopes CP, Barbosa AV. Associação da escoliose toracolombar e peso da mochila em estudantes do ensino médio. Arq Cienc Saude. 2017;24(4): 25-29.

22. de Andrade Ferreira AC, da Silva MRS, Regielle M, da Silva EM, Alves de Souza CE. Análise postural fotogramétrica em adolescentes de escola integral de Caruaru-PE. Rev Inspirar Mov Saude. 2016;8(1):50-57.

23. Braz RG, Goes FPDC, Carvalho GA. Confiabilidade e validade de medidas angulares por meio do software para avaliação postural. Fisioter Mov. 2008;21(3):117-126.

24. Lechner R, Putzer D, Dammerer D, Liebensteiner M, Bach C, Thaler M. Comparison of two-and three-dimensional measurement of the Cobb angle in scoliosis. Int Orthop. 2017;41 (5):957-962

25. Hyndman RJ, Koehler AB. Another look at measures of forecast accuracy. Int J Forecast. 2006;22(4):679-688.

26. Walicka-Cupryś K, Wyszyńska J, Podgórska-Bednarz J, Drzał-Grabiec J. Concurrent validity of photogrammetric and inclinometric techniques based on assessment of anteroposterior spinal curvatures. Eur Spine J. 2018;27(2):497-507.

27. Bland JM, Altman DG. Statistical methods for assessing agreement between two methods of clinical measurement. Lancet. 1986;327(8476):307-310.

28. Fan J, Upadhye S, Worster A. Understanding receiver operating characteristic (ROC) curves. Can J Emerg Med. 2006;8 (1):19-20.

29. Negrini A, Donzelli S, Maserati L, Zaina F, Villafañe JH, Negrini S. Junctional kyphosis: how can we detect and monitor it during growth. Scoliosis Spinal Disord. 2016;11 (2):38

30. Monticone M, Ambrosini E, Cazzaniga D, Rocca B, Ferrante $\mathrm{S}$. Active self-correction and task-oriented exercises reduce spinal deformity and improve quality of life in subjects with mild adolescent idiopathic scoliosis: results of a randomised controlled trial. Eur Spine J. 2014;23(6):1204-1214. 